\title{
Phytochemical analysis and antioxidant defense of kiwifruit (Actinidia deliciosa) against pancreatic cancer and $\mathrm{AAPH}$-induced RBCs hemolysis
}

\author{
Eman Fawzy EL AZAB ${ }^{1,2}$ (D), Heba Sayed MOSTAFA ${ }^{3 *}$ (D)
}

\begin{abstract}
Kiwifruit (Actinidia deliciosa) is a superb nutritional source of phenolic compounds that are beneficial in the prevention of different diseases. The main goal of the current study was to estimate the oxidative activity and compare the effect of the ethanol extract of this fruit's peel and flesh on pancreatic cancer against pancreatic cancer and in vitro 2, 2-azobis-2-amidinopropane dihydrochloride (AAPH) erythrocytes hemolytic oxidative damage. Firstly, HPLC was utilized to identify the phenolic compounds in each extract that showed that $p$-coumaric acid \& ferulic acid (in the peel), syringic acid \& cinnamic acid (in the flesh) were the most abundant. Concerning the anti-cancer effect, flesh extract exhibited more cytotoxic impact as detected by the reduction of PANC-1 cell line viability with $\mathrm{IC}_{50}$ of $232.89 \mu \mathrm{g} / \mathrm{ml}$ contrasted with the $\mathrm{IC}_{50}$ of the peel extract $(556.60 \mu \mathrm{g} / \mathrm{ml})$. Relative to ascorbic acid, both kiwi extracts have been considerably successful in diminishing hemolysis, thiobarbituric acid reactive substances (TBARS) and GSH levels of AAPH-induced RBCs. Interestingly, with $80 \mu \mathrm{g} / \mathrm{ml}$, the ethanol peel extract returned the TBARS and GSH levels to the normal level of RBCs (0.022 and $2.86 \mathrm{nmole} / \mathrm{mg}$ hemoglobin, respectively).
\end{abstract}

Keywords: kiwifruit; polyphenol; anti-hemolytic; TBARS.

Practical Application: The oxidative activity of kiwifruit demonstrates that the flesh has an anti-pancreatic cancer effect while the peel can be utilized as an anti-hemolysis agent as compared with ascorbic acid.

\section{Introduction}

Many diseases, including Alzheimer, inflammation, atherosclerosis, and various kinds of malignant neoplasms, are attributed to macromolecular damage due to imbalanced radical scavenging and propagation of reactive oxygen species (ROS) (Fan et al., 2020; García-Sánchez et al., 2020). Elevated levels of ROS can oxidize biomolecules like DNA, proteins, and lipids leading to tissue damage, cell death, or degenerative processes (Brindisi et al., 2020; Zhang et al., 2020). It is imperative to evaluate and classify unprecedented natural sources of antioxidants for their pivotal function in the scavenging and repression of such radicals (Neha et al., 2019). Phytochemicals from natural sources such as fruits and vegetables have been documented as potential antioxidants (Sharifi-Rad et al., 2020) that are commonly administered in consequence of their vital action in both treatment and prevention of several diseases (Zhao et al., 2017).

Kiwifruit is an edible berry of many species of the Actinidia family. The 'Hayward' cultivar, which belongs to the Actinidia deliciosa genus, is the utmost common and commercially available green kiwifruit (Park et al., 2011). China is the major producer with an annual production of 2196727 tons in 2019; from the harvested area of 182566 ha. Also, New Zealand, Greece, and Italy are among the countries where it is cultivated (Food and Agriculture Organization of the United Nations, 2019).
A wide-ranging of phytochemicals as phenolic, flavonoids, vitamins, carbohydrates, folic acid, minerals, saponins, and tannins compounds have been recognized from kiwifruit extracts following extraction by solvents with various polarities (Bae et al., 2012; D'evoli et al., 2015; Wang et al., 2018; Alim et al., 2019). It contains abundant antioxidant compounds that facilitate its use in the treatment and prevention of a broad range of clinical conditions, including digestive disorders, rheumatism, dyspepsia, and cardiovascular diseases (Leontowicz et al., 2014; Podsedek et al., 2014; Peticila et al., 2015). The challenging anti-proliferative activity of kiwifruit towards human hepatocellular (HepG2), colon (HT-29), and gastric (GC) cell lines (Zuo et al., 2012; Lim et al., 2016) has already been demonstrated.

To our knowledge, no foregoing study has inspected the upshot of kiwifruit on pancreatic cancer cells or as an anti-hemolytic agent. Thus, the purpose of the current study is to examine and compare the phenolic and flavonoid content and the unique phenolic profile using HPLC of the ethanol extract of flesh and pericarp of Actinidia deliciosa. Comparing the biological functions of both extracts, such as pancreatic anti-cancer and anti-hemolytic action is the most significant objective. 


\section{Materials and methods}

\subsection{Chemicals}

Quercetin and nitro blue tetrazolium chloride were purchased from Cayman Chemical Co., USA. 3-4, 5-dimethyl-thiazol-2yl)-2, 5-diphenyl tetrazolium bromide (MTT) was purchased from Bio basic Inc., Canada while, RPMI-1640 medium was from Gibco; Thermo Fisher Scientific, Waltham, MA, USA, and fetal bovine serum (FBS) was obtained from Biological Industries, Cromwell, CT, USA. All other chemicals were of the analytical grades that were imported from Sigma-Aldrich Co., Germany.

\subsection{Fruit extract preparation}

Actinidia deliciosa (kiwifruit) was acquired from the local market in the season of July 2020. First, the flesh was separated from the skin, then homogenized by a high-speed hand blender. The ethanol extract was prepared by combining the flesh or peels separately with $70 \%$ ethanol $(1: 1 \mathrm{w} / \mathrm{v})$ for $24 \mathrm{~h}$ at $30{ }^{\circ} \mathrm{C}$. Subsequently, the filtrates were concentrated using a rotary vacuum evaporator (Buchi CH-9230, Germany) and thereafter lyophilized (Xiangyi, FD-10 Bench-top, China) and stored at $-80^{\circ} \mathrm{C}$ until use. The lyophilized powder was dissolved in ethanol $70 \%$ unless stated for the next experiments.

\subsection{Total phenolic and flavonoid content estimation}

Using the Folin-Ciocalteu reagent, total phenolic (TP) content was quantified as Singleton et al. (1999) method. By mixing $500 \mu \mathrm{l}$ of fruit extract or methanol as a blank with $2500 \mu \mathrm{l}$ of Folin-Ciocalteu reagent (10\%) and $2500 \mu \mathrm{l}$ of $7.5 \% \mathrm{NaHCO}_{3}$, the experiment tubes were incubated at $45{ }^{\circ} \mathrm{C}$ for $45 \mathrm{~min}$. Total flavonoid (TF) was estimated by Didry et al. (1990) test, where $250 \mu \mathrm{l}$ from each diluted extract was blended separately with $(\mu \mathrm{l})$ : 750 of $95 \%$ ethanol, 50 of $10 \%$ aluminium chloride, 50 of $1 \mathrm{M}$ potassium acetate, and 1400 of distilled water, then incubated at $25^{\circ} \mathrm{C}$ for 30 minutes. Finally, the absorbance of polyphenols and flavonoids mixture was read at 765 and $415 \mathrm{~nm}$, respectively using UV-Spectrophotometer (Alpha-1502, USA). The amounts of TP and TF were valued as the equivalent gallic acid (GAE) and quercetin (QE)/g extract, respectively.

\subsection{Phenolic compounds profile}

The HPLC system of Singh et al. (2002) (pump PU-1580, UV detector UV-1570, injector equipped with a $20 \mu \mathrm{L}$ loop) was used. The sample was separated using a $250 \times 4$.6- mm stainlesssteel column discovery- $\mathrm{C} 184 \mu \mathrm{m}$. The running conditions were maintained at a flow rate of $1 \mathrm{ml} / \mathrm{min}$, and the temperature was at $25{ }^{\circ} \mathrm{C}$. The solvent $\mathrm{A}$ was water containing $0.05 \%$ formic acid, and solvent B: acetonitrile/methanol (80:20, v/v). Each lyophilized kiwifruit extract sample $(0.5 \mathrm{~g})$ was extracted using ethanol (70\%), then filtered and injected. The gradient conditions were as follows: $0-5 \mathrm{~min}, 10 \% \mathrm{~B}$; 5-15 min, $10-18 \% \mathrm{~B} ; 15-25 \mathrm{~min}, 18 \% \mathrm{~B}$; 25-30 min, 18-25\% B; 30-35 min, 25\% B; 35-40 min, 25-35\% B; 40-45 min, 35-60\% B; 45-50 min 60-10\% B; and 50-55 min with $10 \% \mathrm{~B}$. The temperature of the column was controlled at $25^{\circ} \mathrm{C}$. Phenolic compounds existent in each extract have been defined by comparing the retention time (Rt) to the individual standards.

\subsection{Anti-pancreatic cancer activity estimation}

\author{
PANC-1 cell culture conditions
}

The human pancreatic cancer cell line PANC-1 (CRL-1469, isolated from a pancreatic carcinoma of ductal cell origin of a 56-year-old male) was purchased from American Tissue Cell Culture (ATCC, Manassas, VA, USA) then preserved in RPMI1640 growth medium containing $2 \%$ fetal bovine serum (FBS). All media contained 100 units $/ \mathrm{ml}$ penicillin and $100 \mu \mathrm{g} / \mathrm{ml}$ streptomycin. The cell line was held at $37^{\circ} \mathrm{C}$ in a humidified incubator with $\mathrm{CO}_{2}(5 \%)$. For the experiment, cells that had reached the exponential growth phase were chosen.

\section{MTT assay}

Rendering to the procedure of van de Loosdrecht et al. (1994), the anti-cancer activity was done using MTT assay. PANC-1 cells in the exponential growth phase were inoculated on 96-well plates at a density of $1 \times 10^{5}$ cells/ml $(100 \mu$ l per well $)$, and sterile phosphate buffer saline (PBS) was added to the edge as well as a blank control. The plate was incubated at $37^{\circ} \mathrm{C}$ with $5 \% \mathrm{CO}_{2}$ for one day to enable the cells' attachment. When the PANC-1 cells reached full confluence, the medium was withdrawn, and the monolayer cells were washed two times with $1 \mathrm{ml}$ of trypsin $(0.25 \%) /$ EDTA $(0.05 \%)$ solution. The sample extract was first diluted in an RPMI medium (containing 2\% serum), then $0.1 \mathrm{ml}$ of each dilution was pipetted in each well, while the control well only contained the RPMI medium. At $37^{\circ} \mathrm{C}$, the incubated plates were examined for toxicity signs. Finally, $20 \mu \mathrm{l} \mathrm{MTT}(5 \mathrm{mg} / \mathrm{ml}$ PBS) was applied to each well, and then incubated for 1-5 h at $37{ }^{\circ} \mathrm{C}$ in $5 \% \mathrm{CO}_{2}$. To dissolve formazan (MTT metabolic product), two hundred $\mu \mathrm{l}$ of DMSO was poured into each well then stirred. Using a microplate reader (MR-96A, Mindray, China), the absorbance at $560 \mathrm{~nm}$ was recorded. The survival cell percentage was calculated using the next Equation 1:

$\%$ Cell viability $=\frac{\mathrm{A} \text { treated cell }}{\mathrm{A} \text { control cells }} \times 100$

\subsection{Anti-hemolytic activity estimation}

\section{RBCs separation}

From healthy Albino rats, the blood samples were obtained, then centrifuged $(1000 \mathrm{xg})$ for ten minutes. After disposal of the supernatant, the pellet was re-washed and centrifuged 3-times with PBS (pH 7.4). Red blood cells (Erythrocytes, RBCs) were finally suspended in the same buffer to obtain approximately $50 \%$ hematocrit, stored at $4{ }^{\circ} \mathrm{C}$ and used within $6 \mathrm{~h}$ in the next experiments (Miki et al., 1987).

\section{Measurement of RBCs hemolysis induced by AAPH}

2, 2-azobis-2-amidinopropane dihydrochloride (AAPH) triggered erythrocyte hemolysis was quantified using the adapted method of Miki et al. (1987). Two hundred $\mu$ l of each kiwi extract (100 to $500 \mu \mathrm{g} / \mathrm{ml}$ ) were applied successively to $200 \mu \mathrm{l}$ of AAPH (100 mM) with $200 \mu$ l of the previously obtained erythrocyte 
suspension, then incubated with mild shaking at $37^{\circ} \mathrm{C}$ for $3 \mathrm{~h}$. Finally, the experiment tubes were diluted 20 times with PBS and centrifuged (at $1500 \mathrm{x}$ g for $10 \mathrm{~min}$ ) then $A_{540}$ was recorded. The reference value was evaluated by mixing the hemolyzed erythrocytes with the hypotonic buffer $(5 \mathrm{mM}$ phosphate buffer pH 7.4; hemolysis of 100 percent). The next Equation 2 was applied to calculate the percentage of hemolysis:

$\%$ Hemolysis $=\frac{\text { A sample supernatent }}{\text { Reference value }} \times 100$

Measurement of RBCs lipid peroxidation inhibition induced by $A A P H$

Erythrocytes were pre-incubated for a half-hour at $37^{\circ} \mathrm{C}$ with varying concentrations of each kiwi extract, or ascorbic acid as a guide $(20-100 \mu \mathrm{g} / \mathrm{ml})$ or $0.2 \%$ ethanol as a negative control. Subsequently, $25 \mathrm{mM}$ AAPH was applied to the erythrocytes suspension (5\%) and incubated for $3 \mathrm{~h}$ at $37^{\circ} \mathrm{C}$ with kind shaking. To interrupt the reaction, two $\mathrm{ml}$ of thiobarbituric acid reagent $(0.375 \% \mathrm{TBA}, 15 \% \mathrm{TCA}$ in $0.2 \mathrm{M} \mathrm{HCl})$ were used, after $1 \mathrm{~h}$ incubation in a boiling water bath. Finally, after cooling and centrifugation (at $1500 \mathrm{x} \mathrm{g}$ for 5 minutes), thiobarbituric acid reactive substances (TBARS) was spectrophotometrically monitored at wavelength $535 \mathrm{~nm}$ and valued per mg of hemoglobin (Borra et al., 2013).

\section{Measurement of the reduced glutathione (GSH) concentration in hemolyzed RBCs}

Using DTNB, known as Ellman's reagent, the GSH concentration was measured (Kunwar et al., 2007). Suspension of RBCs (5\%) was subjected to hemolysis by $25 \mathrm{mM}$ AAPH for $3 \mathrm{~h}$, in the incidence of varying concentrations of each extract, precipitated by $10 \%$ TCA and then centrifuged $(1500 \mathrm{x} \mathrm{g})$ for $15 \mathrm{~min}$. To $1000 \mu \mathrm{l}$ of the supernatant, half $\mathrm{ml}$ of Ellman's reagent plus $3 \mathrm{ml}$ of phosphate buffer ( $\mathrm{pH} \mathrm{8}$ ) was added. The yellow color established was read at wavelength $412 \mathrm{~nm}$ against the blank (distilled water) and GSH level was expressed as nmole $\mathrm{DTNB} / \mathrm{mg}$ of hemoglobin.

\subsection{Anti-oxidative activity estimation}

\section{Superoxide scavenging assay}

It was determined in both extracts as the procedure of Nishikimi et al. (1972). One ml of each kiwi extract (in concentrations from 10 to $50 \mu \mathrm{g} / \mathrm{ml}$ ) was blended with $1 \mathrm{ml}$ from both nitro blue tetrazolium $(156 \mu \mathrm{M})$ and NADH $(468 \mu \mathrm{M})$ in PBS $(0.1 \mathrm{M}, \mathrm{pH} 7.4)$ solutions. Reduced absorbance $\left(A_{560}\right)$ indicated an increase in the scavenging percent as calculated by Equation 3 .

$\%$ Scavenging $=\frac{\text { A blank }- \text { A sample }}{\text { A blank }} \times 100$

\section{Hydroxyl scavenging assay}

One $\mathrm{ml}$ of varying concentrations from each extract (20$100 \mu \mathrm{g} / \mathrm{ml}$ ) was added to $2 \mathrm{ml}$ of $\mathrm{H}_{2} \mathrm{O}_{2}$ solution ( $20 \mathrm{mM}$ in PBS).
After $10 \mathrm{~min}$, the absorbance was estimated at $230 \mathrm{~nm}$ against a blank solution made up of $\mathrm{H}_{2} \mathrm{O}_{2}$. The percentage of scavenging was determined by Equation 3 (Ma et al., 2019).

\subsection{Statistical analysis}

The data were statistically analyzed by ANOVA test using SPSS version 20 at $p<0.05$, then presented as the average of three replicates \pm standard deviation (SD). The 50 percent inhibitory concentration $\left(\mathrm{IC}_{50}\right.$ ) was determined from the dose-response curve (Graph Pad Prism Version 6.0) achieved by plotting percent inhibition towards the different concentrations.

\section{Results and discussion}

\subsection{Total phenolic (TP) and flavonoid (TF) content}

The TP content, as determined by Folin-Ciocalteu reagent, was 14.2 and $10.2 \mathrm{mg} \mathrm{GAE} / \mathrm{g}$ dry weight for the kiwi peel and flesh, respectively. The results verified that the phenolic content in the kiwi peel extract was $39.2 \%$ higher than flesh ethanol extract. TP content was estimated from the linear regression equation where $\mathrm{R}^{2}=0.989$.

The most popular set of polyphenol substances in the human diet is flavonoids. Flavonoids have many biological activities such as antimutagenic, antiviral, and anti-oxidation (Alim et al., 2019). The TF content in kiwi peel (3.9 mg QE/g) was meaningfully higher $(p<0.05)$ than in flesh extract $(1.6 \mathrm{mg} \mathrm{QE} / \mathrm{g})$, indicating that peel extract contained more than twice the flavonoid amount of the flesh. The TF was calculated by the equation of linear regression where $R^{2}=0.991$.

These findings are harmonious with other authors who found $16.67 \pm 2.83 \mathrm{mg} \mathrm{GAE} / \mathrm{g}$ and $12.95 \pm 0.52 \mathrm{mg} \mathrm{QE} / \mathrm{g}$ in the lyophilized aqueous kiwi extract (Bursal \& Gülçin, 2011), and $9.60 \mathrm{mg} \mathrm{GAE} / \mathrm{g} \mathrm{dw} \& 92.1 \mu \mathrm{g}$ catechin $(\mathrm{CE}) / \mathrm{g} \mathrm{dw}$ in methanol extract of A. deliciosa pulp (Park et al., 2011). Alim et al. (2019) and Wang et al. (2018) have also ensured our results that the peel extract has an elevated degree of phenolic and flavonoids content in contrast with the flesh extract, 28.79 vs. $15.44 \mathrm{mg} \mathrm{GAE} / \mathrm{g}$ and 13.96 vs. $2.1 \mathrm{mg}$ rutin/g dw, respectively.

\subsection{HPLC analysis}

To recognize the exact polyphenols in each lyophilized kiwifruit ethanol extract, the polyphenol composition was explored as appeared in Figure 1 and concentrations thereof in Table 1. Ten phenolic compound standards have been detected, including five hydroxycinnamic acids (ferulic, caffeic, chlorogenic, cinnamic and p-coumaric acids), two hydroxybenzoic acids (syringic acid and ellagic acid), one flavonol (quercetin), and two flavan-3-ols $((+)$-catechin and it's derivative: catechol). The overall content of polyphenols in the ethanol extract of kiwi peel surpasses the flesh content, which is consistent with other studies (Bursal \& Gülçin, 2011; Wang et al., 2018). Results indicated that syringic acid $(11.25 \mathrm{mg} / \mathrm{kg})$ was the key phenolic compound in kiwi pulp extract. It was accompanied by cinnamic acid $(10.25 \mathrm{mg} / \mathrm{kg})$ and ellagic acid $(7.14 \mathrm{mg} / \mathrm{kg})$ with low levels of catechin and quercetin. On the opposite 
hand, the most plentiful phenolic compounds in kiwi peel extract were hydroxycinnamic acids i.e. $p$-coumaric acid and ferulic acid (15.5 and $10.3 \mathrm{mg} / \mathrm{kg}$, correspondingly) that are rarely enclosed in kiwi flesh. Other researchers figured that the dominant components of phenolics in the kiwi flesh were $(+)$-catechin, chlorogenic acid, rutin, (-)-epicatechin and quercetin (Kim et al., 2009). Rutin and quercetin were detected by Wang et al. (2018) in both the flesh and peel extract of A. deliciosa cv. Hawyard, but the chief phenolic compound was L-epicatechin. The divergences between our findings may be attributable to the diverse kiwifruit cultivars, cultivation conditions and the solvent used.

\subsection{Anti-pancreatic cancer effect}

Due to its rapid growth, early metastases, and poor response to any known therapies, pancreatic cancer stands as one of the troublesome types of cancer. As the fourth reason for cancer mortality and with anticipation of being the second cause after lung cancer in 2030, there is an immediate need to discover natural and healthy food to prevent such disease (Aizikovich, 2020). Figure 2 demonstrates the cytotoxic impact of the ethanol extract of kiwi flesh and peels on PANC-1 cells viability as estimated by the MTT assay. Both extracts have been able to decrease the viability rate of the tumor cells in a dosagedependent manner. The flesh has potent cytotoxicity compared to kiwi peels. More than $90 \%$ of PANC- 1 cells died at $1000 \mu \mathrm{g}$ flesh extract $/ \mathrm{ml}$. By increasing the concentration of the peel extract from 125 to $1000 \mu \mathrm{g} / \mathrm{ml}$, the growth rate of cells decreased from 99.71 to $22.22 \%$. The same illustration also demonstrated the dosage needed for $50 \%$ inhibition $\left(\mathrm{IC}_{50}\right.$ ) of $232.89 \mu \mathrm{g} / \mathrm{ml}$ for kiwi flesh and $556.6 \mu \mathrm{g} / \mathrm{ml}$ for peel extract. The morphological specification of the treated cell line, as opposed to the untreated cells, is shown in Figure 3. The cells treated with each extract

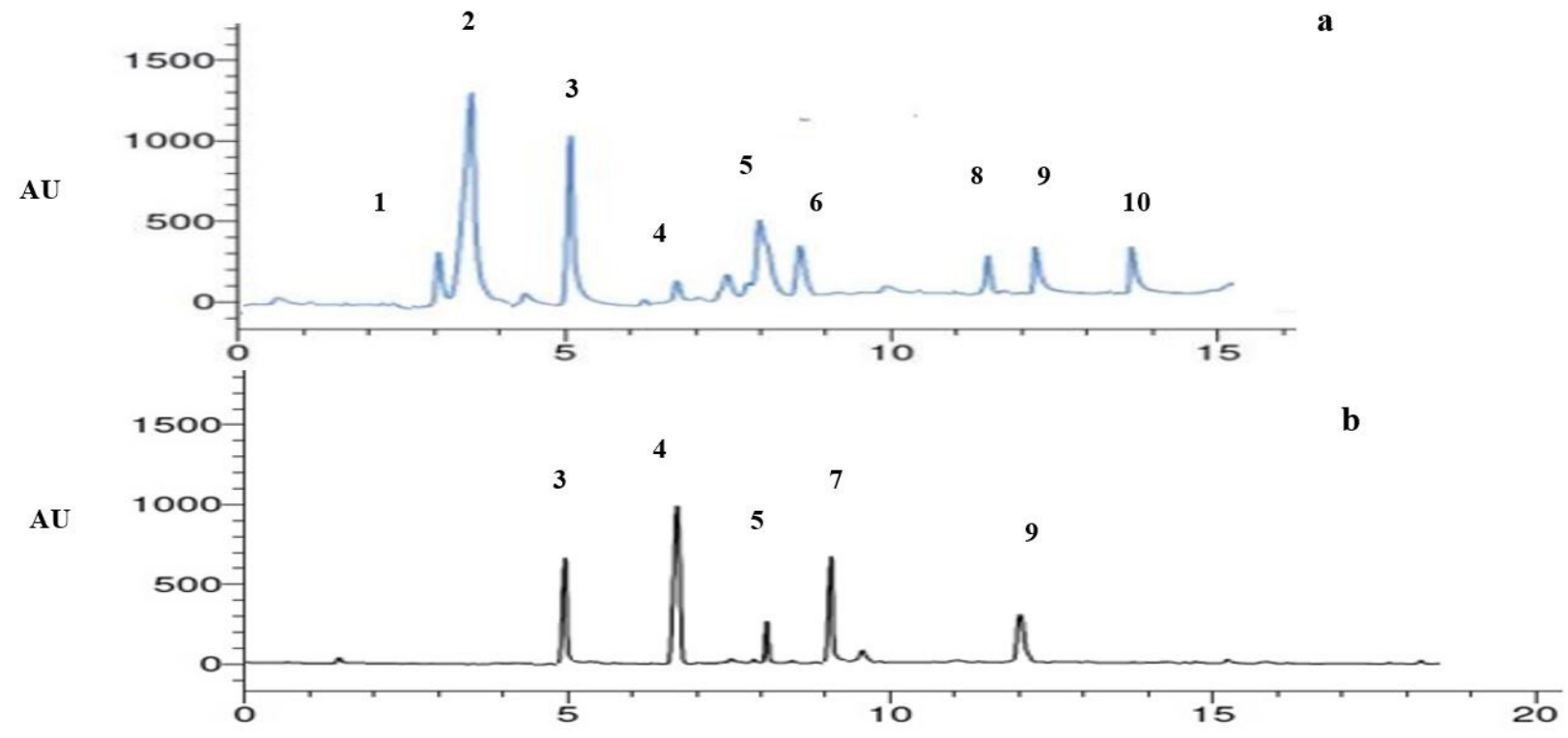

Retention time (min)

Figure 1. HPLC chromatograms of the free phenolic compounds of the kiwifruit ethanolic extracts. (a) Flesh extract; (b) Peel extract. 1: Catechin, 2: Syringic acid, 3: Cinnamic acid, 4: $p$-Coumaric acid, 5: Ellagic acid, 6: Caffeic acid, 7: Ferulic acid, 8: Catechol, 9: Chlorogenic acid, 10: Quercetin.

Table 1. The Content of phenolic compounds in kiwifruit ethanol extracts ( $\mu \mathrm{g} / \mathrm{g} \mathrm{DW})$ as detected by HPLC (mean, $\mathrm{n}=3$ ).

\begin{tabular}{cccccc}
\hline No. & Retention time $(\mathrm{min})$ & Phenolic compound & Molecular weight & Flesh extract & Peel extract \\
\hline 1 & 2.99 & Catechin & 290.26 & 1.20 & - \\
2 & 3.30 & Syringic acid & 198.17 & 11.25 & - \\
3 & 5.10 & Cinnamic acid & 148.16 & 10.25 & 0.73 \\
4 & 6.99 & p-coumaric acid & 164.04 & 7.14 & -25 \\
5 & 8.01 & Ellagic acid & 302.19 & 6.55 & - \\
6 & 9.12 & Caffeic acid & 180.16 & - & 1.02 \\
7 & 9.00 & Ferulic acid & 194.18 & 1.22 & - \\
8 & 11.20 & Catechol & 110.11 & 2.31 & 6.29 \\
9 & 12.10 & Chlorogenic acid & 354.31 & 2.55 & - \\
10 & 14.00 & Quercetin & 302.23 & 42.00 & 45.36 \\
\end{tabular}


exhibited morphological cell death characteristics such as wrinkles, rounding and the resignation of the cells, which increased by increasing the extract concentrations.

Our results established that the anti-pancreatic adenocarcinoma activity of kiwi flesh was more potent than that of peels. This was strongly associated with its phenolic profile and the compounds found, in particular quercetin, caffeic acid and syringic acid, which mainly exist in the extract of the flesh and not found in the peel. Quercetin is a pleiotropic kinase inhibitor that has demonstrated its anti-pancreatic effect (Russo et al., 2014), while caffeic and syringic acids have an inhibitory effect on different cancer cells proliferation (Rajendra Prasad et al., 2011). This finding is controversial with previous results of Alim et al. (2019) where ethanol extract of kiwi (A. Chinensis) flesh and peel exhibited HepG2 anti-proliferation with $\mathrm{IC}_{50}$ of 291 and $170 \mu \mathrm{g} / \mathrm{ml}$, respectively. In contrast, acetone extract of kiwi peels (A. deliciosa) did not have any effect on breast MCF-7 and hepatocellular carcinoma HepG2 cell lines (Salama et al., 2018). The methanol extract $A$. aruguta pulp showed an anti-proliferative effect on Hep3B and Hela $\left(\mathrm{IC}_{50}\right.$ of 0.3 and $\left.0.2 \mu \mathrm{g} / \mathrm{ml}\right)$ but not

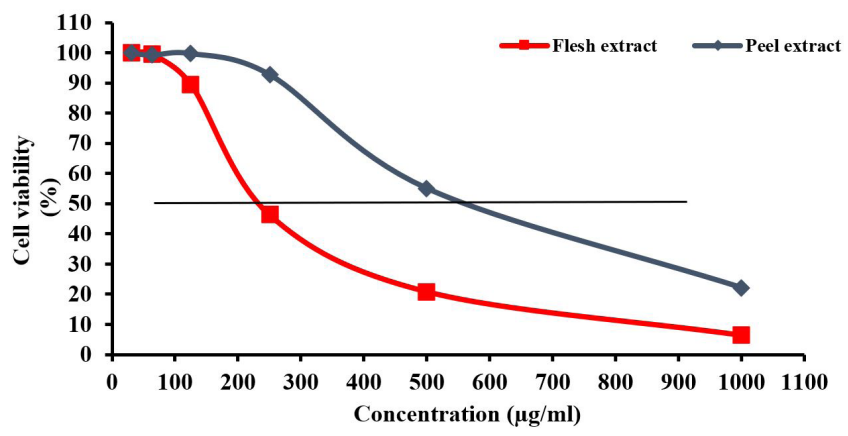

Figure 2. Effect of ethanol extracts of kiwifruit on the PANC-1 cell line viability. on LoVo, HepG2, HT29 cell lines (Lim et al., 2016). Our study covers the aspects of new evidence for the upshot of kiwifruit on pancreatic cancer that has not been previously demonstrated.

\subsection{Anti-hemolytic effect}

\section{Inhibition of RBCs hemolysis}

Erythrocytes hemolysis is considered a perfect model for stating the free radical intermediate oxidative damage to the cell membrane and for evaluating the anti-oxidation action (Qin et al., 2020). AAPH has been proven to influence hemolysis by raising intracellular free radicals. The proteins and lipids of the erythrocyte membrane are eventually attacked by ROS or free radicals, which are very responsive in nature, causing irreversible damage. Typically, this process ends with erythrocyte hemolysis or the degradation of healthy erythrocytes (Yang et al., 2017; Rashidpoura et al., 2021). The scavenging of peroxyl radicals was therefore investigated using different concentrations of kiwi flesh and peel extracts and standard ascorbic acid to estimate the activity of kiwi fruit against AAPH-induced hemolysis of RBCs. The study demonstrated that the hemolysis percentage diminished in a concentration-dependent way (Figure 4) when the ethanol extract of kiwifruit (between 100 and $500 \mu \mathrm{g} / \mathrm{ml}$ ) was applied. At $100 \mu \mathrm{g} / \mathrm{ml}$ extract concentration, when kiwi flesh, peel, and ascorbic acid were added, the percentage of RBCs hemolysis was $88.23 \%, 78.71 \%$ and $62.49 \%$, correspondingly. Maximum inhibition of RBCs hemolysis was recorded, at a concentration of $500 \mu \mathrm{g} / \mathrm{ml}$, by ascorbic acid (25.07\%) afterwards, the peels extract (42.92\%) then by the flesh extract (58.19\%). Generally, the kiwi peel extract demonstrated a significantly higher value compared to the kiwi flesh extract $(p<0.05)$. In addition, either kiwi flesh or peel extract exhibited slightly lesser values $(p<0.05)$ than their reference. The $\mathrm{IC}_{50}$ was found to be $597.94 \pm 2.3 \mu \mathrm{g} / \mathrm{ml}$ for pulp, $387.37 \pm 2.1 \mu \mathrm{g} / \mathrm{ml}$ for peel, and $201.36 \pm 2.9 \mu \mathrm{g} / \mathrm{ml}$ for

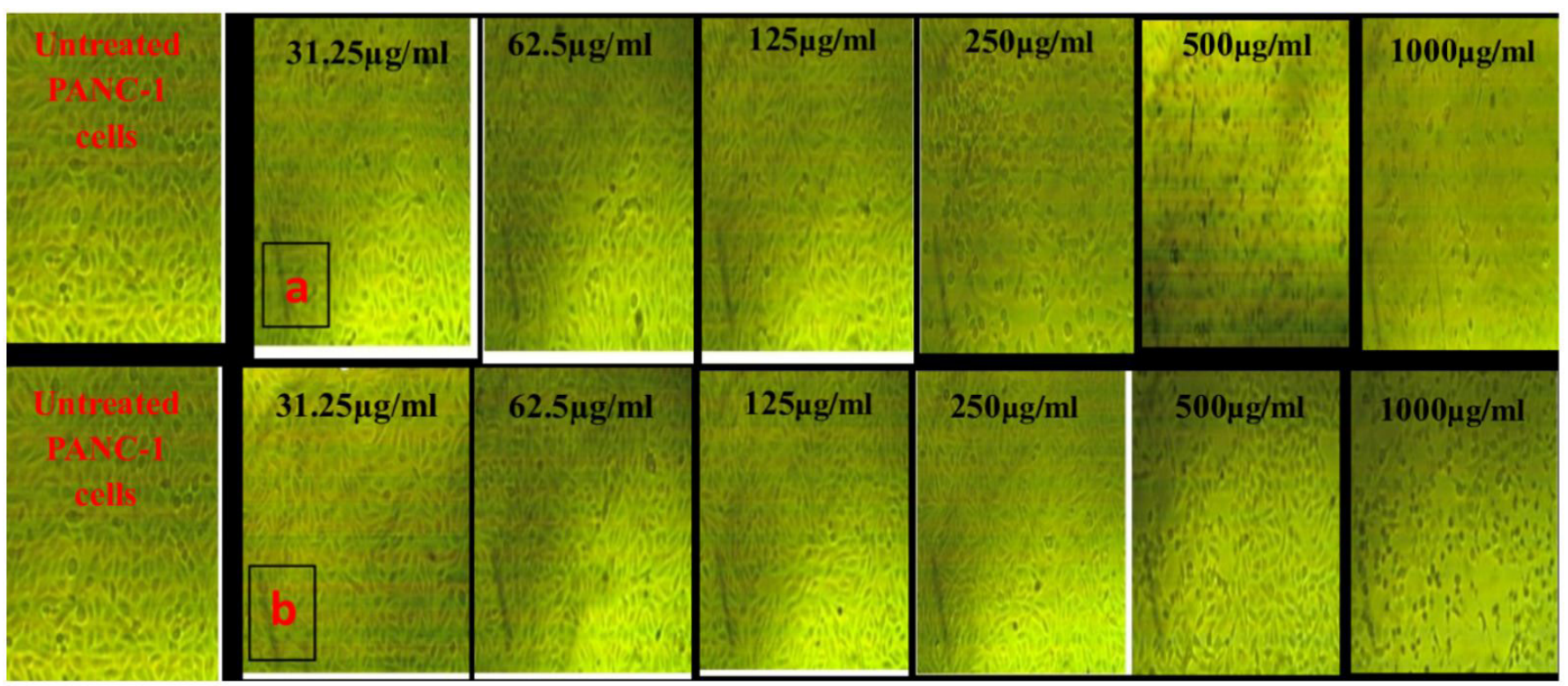

Figure 3. Comparison of cytotoxicity effect of (a) kiwi flesh and (b) kiwi peel extracts at different concentrations on PANC-1 cells compared with untreated cells. 
the standard ascorbic acid. Kiwi peel is moderately effective in preventing progressive hemolysis of RBCs. It may be related to the identified antioxidant phenolic compound, ellagic acid, which is naturally synthesized in plants as a protectant against infections and pests (Vattem \& Shetty, 2005). This study highlighted the positive cellular anti-oxidative abilities of kiwifruit for the first time, which had previously been documented by other plants extracts as mulberry leaves (Choi et al., 2013), pomelo fruit (Wang et al., 2019), and osthole as an active component of Cnidium monnieri (Rashidpoura et al., 2021).

\section{Inhibition of RBCs lipid peroxidation}

Just as the membrane of erythrocytes is rich in polyunsaturated fatty acids, AAPH-initiated radicals can oxidize membrane lipids at physiological temperature, causing rapid membrane injury and destruction of integrity, prompting lipid peroxidation (Yang et al., 2017; Rashidpoura et al., 2021). In this examination, the lipid peroxidation rate of RBCs was estimated by calculating TBARS released. Figure 5 shows the varying amounts of TBARS in RBCs (after AAPH-induced harm) without or with various concentrations of kiwi flesh and peel extracts, contrasted with ascorbic acid. The standard baseline level of TBARS was established to be $0.024 \pm 0.03 \mathrm{nmole} / \mathrm{mg}$ hemoglobin in RBCs (without AAPH); and when incubated with AAPH, the TBARS level increased to $0.092 \pm 0.07 \mathrm{nmole} / \mathrm{mg}$ hemoglobin. In the case of kiwifruit flesh and peel extracts, or ascorbic acid, there was indeed a steady decline in the TBARS level in AAPHinduced RBCs, and this inhibition increased with increasing the concentrations tested. For example, at a concentration of $20 \mu \mathrm{g} /$ ml, TBARS formation was significantly diminished $(p<0.05)$ by ascorbic acid and kiwi flesh and peel extracts starting from 0.092 to $0.063,0.059$, and 0.052 nmole of TBARS/mg hemoglobin, respectively. In general, all kiwi extracts have been substantially more effective in reducing TBARS levels of RBCs than ascorbic acid. Overall, the lipid peroxidation inhibition by kiwi peel extract at all concentrations was visibly higher than the flesh $(p<0.05)$. Obviously, peel extract returned the TBARS level at 80 and $100 \mu \mathrm{g} / \mathrm{ml}$ concentrations to the normal basal level of natural RBCs (0.022 nmole/mg hemoglobin). Since kiwifruit is rich in ascorbic acid and polyphenols, we assume that these components may have contributed to inhibiting AAPH-induced

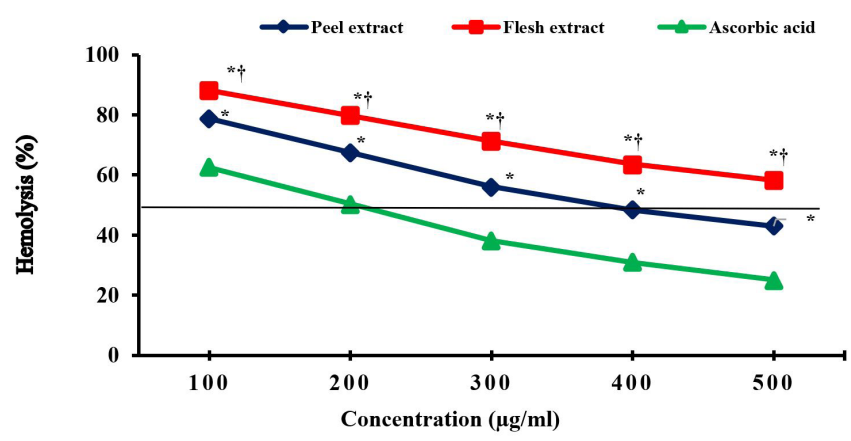

Figure 4. Effect of kiwi peel and flesh extracts against AAPH-induced hemolysis compared with ascorbic acid. ${ }^{*}$ Results of flesh or peel extract are significant at $\mathrm{p}<0.05$ compared with ascorbic acid. $\dagger$ Results of flesh extract are significant at $\mathrm{p}<0.05$ compared with the peel extract. free radical development and preventing free radical-induced oxidative hemolysis. No published work has inspected the impact of kiwifruit on RBCs hemolysis. Further research is needed to distinguish and extract the particular compounds responsible for this phenomenon from kiwifruit.

\section{The reduced glutathione (GSH) concentration in hemolyzed RBCs}

The most plenteous thiol segment found in mammalian cells is GSH, which has a diversity of pivotal cell functions as keeping up the essential thiol status of proteins by preventing oxidation of sulfahydryl groups, dipping disulphide bonds induced by oxidative stress, or by free radicals scavenging. Through oxidative stress, the cellular pool of GSH has declined (Zhang et al., 2014). Thus, cellular GSH depletion is well-known to be a foot marker of oxidative stress and correlated with increased lipid peroxidation and protein oxidation (Yang et al., 2017; Rashidpoura et al., 2021). Figure 6 shows the changes in GSH levels of RBCs following AAPH induction with the presence of different kiwi flesh and peel extracts concentrations $(20-100 \mu \mathrm{g} / \mathrm{ml})$, compared to ascorbic acid. The normal basal GSH level in RBCs (control) was found to be $2.86 \pm 0.19 \mathrm{nmole} / \mathrm{mg}$ hemoglobin. Incubation of erythrocytes with AAPH ( $25 \mathrm{mM})$ for $3 \mathrm{~h}$ caused a greater diminution $(\approx 57 \%)$ in the glutathione level from the basal to $1.23 \pm 0.27 \mathrm{nmole} / \mathrm{mg}$ hemoglobin. The dramatic drop in GSH levels suggests that exposure to AAPH is severe oxidative stress. In the existence of kiwi flesh and peel extracts or ascorbic acid, a gradual upsurge in GSH levels with increasing concentrations was observed. Results also display that all the tested concentrations of kiwi extracts or ascorbic acid, significantly increased GSH level in RBCs treated with AAPH. Relative to ascorbic acid, kiwi peels and flesh extracts have been found to significantly improve $(p<0.05)$ the GSH level. At two concentrations (80 and $100 \mu \mathrm{g} / \mathrm{ml})$, the GSH of RBCs treated with kiwi peel extract reached the control level $(2.86 \pm 0.19 \mathrm{nmole} / \mathrm{mg}$ hemoglobin) with no significant variations. The observed decrease in GSH levels in kiwifruit extracts AAPH-pretreated RBCs samples may be due to an excess accumulation of phenoxyl radicals, which oxidizes cellular GSH to GSSG (Choi et al., 2013). The elevation of erythrocyte GSH levels by kiwifruit extracts; supports the antioxidant properties of this fruit, which may point to lower levels of TBARS. It mainly correlated with the protective power of the identified polyphenols, especially ellagic acid, caffeic acid, syringic acid and quercetin (Choi et al., 2013). Once more, we have given proof that kiwifruit has an outstanding antioxidant activity against AAPH-induced GSH depletion in RBCs higher than pure ascorbic acid. However, their mechanism of action in cell signaling related molecules warrants future investigation.

\subsection{Anti-oxidative activity}

It was critical to examine the anti-oxidative efficiency of the extracts prepared in order to attribute the critical role of natural antioxidants in the scavenging and inhibition of free radicals demonstrated in the previous experiments. Consequently, besides the estimation of individual bioactive compounds (e.g. polyphenols and flavonoids) in each extract, two not common complemented antioxidant activity assays have been determined. $\mathrm{HO} \bullet$ and superoxide anion are the utmost active anions among 


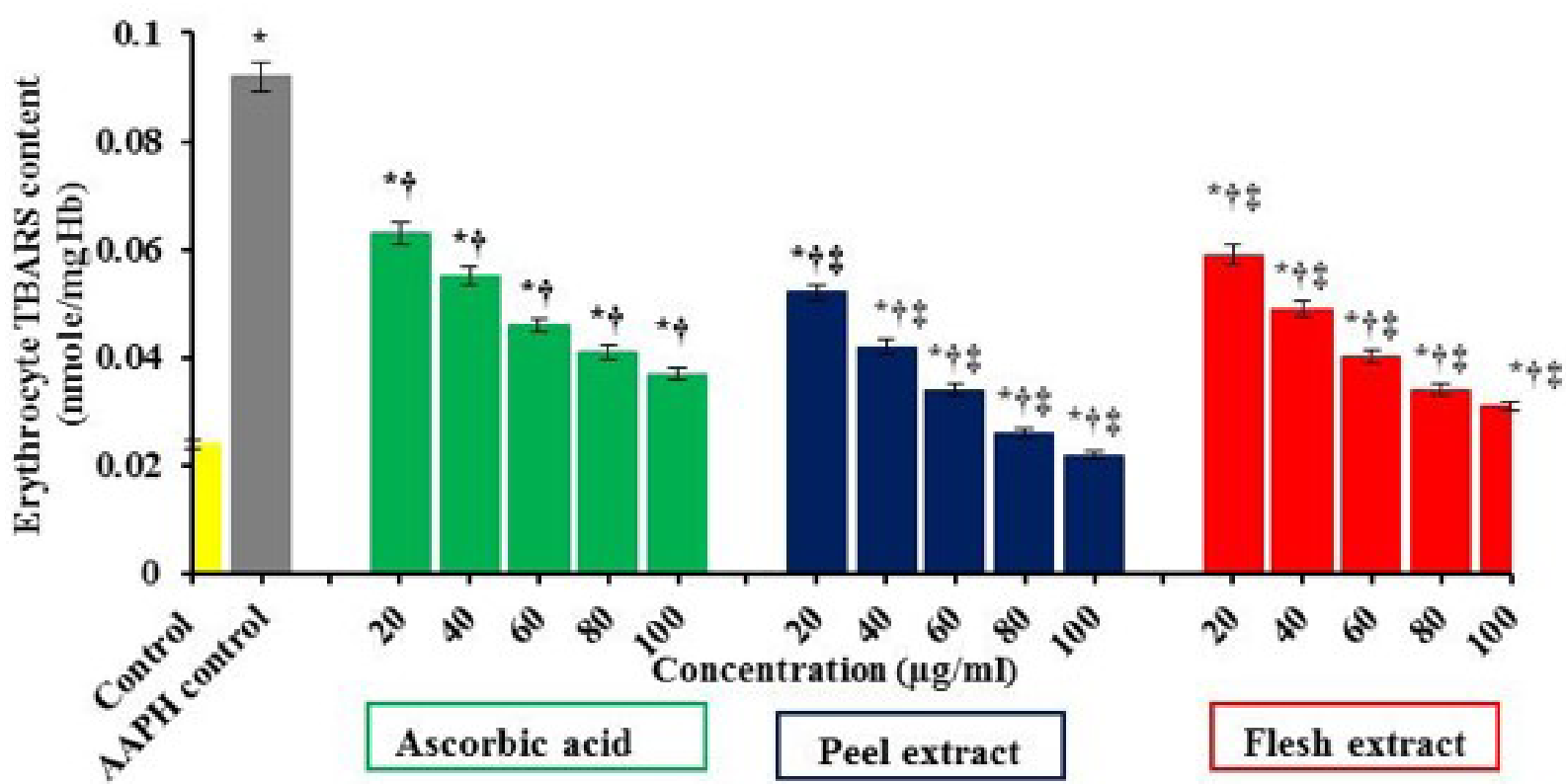

Figure 5. The TBARS levels of AAPH-induced erythrocytes restored by the kiwi peel and flesh extracts. Erythrocyte suspension at $5 \%$ hematocrit was incubated with PBS (control) or pre-incubated with different concentrations of peel, flesh or ascorbic acid $(20-100 \mu \mathrm{g} / \mathrm{ml})$ for $30 \mathrm{~min}$. Then, the erythrocytes were incubated with AAPH $(25 \mathrm{mM})$ for $3 \mathrm{~h}$. Erythrocyte TBARS content was expressed as nmole/mg Hb. Values are expressed as Mean $(n=3) \pm S D$. ${ }^{*}$ : Results are significant at $\mathrm{p}<0.05$ compared with untreated control cells. $\dagger$ : Results are significant at $\mathrm{p}<0.05$ compared with cells treated with AAPH alone. $\neq$ : Results of flesh extract or peel extract are significant at $\mathrm{p}<0.05$ compared with the same concentration of ascorbic acid. AAPH: 2, 2'-azobis (2-amidinopropane) dihydrochloride; PBS: Phosphate buffer saline; SD: Standard deviation.

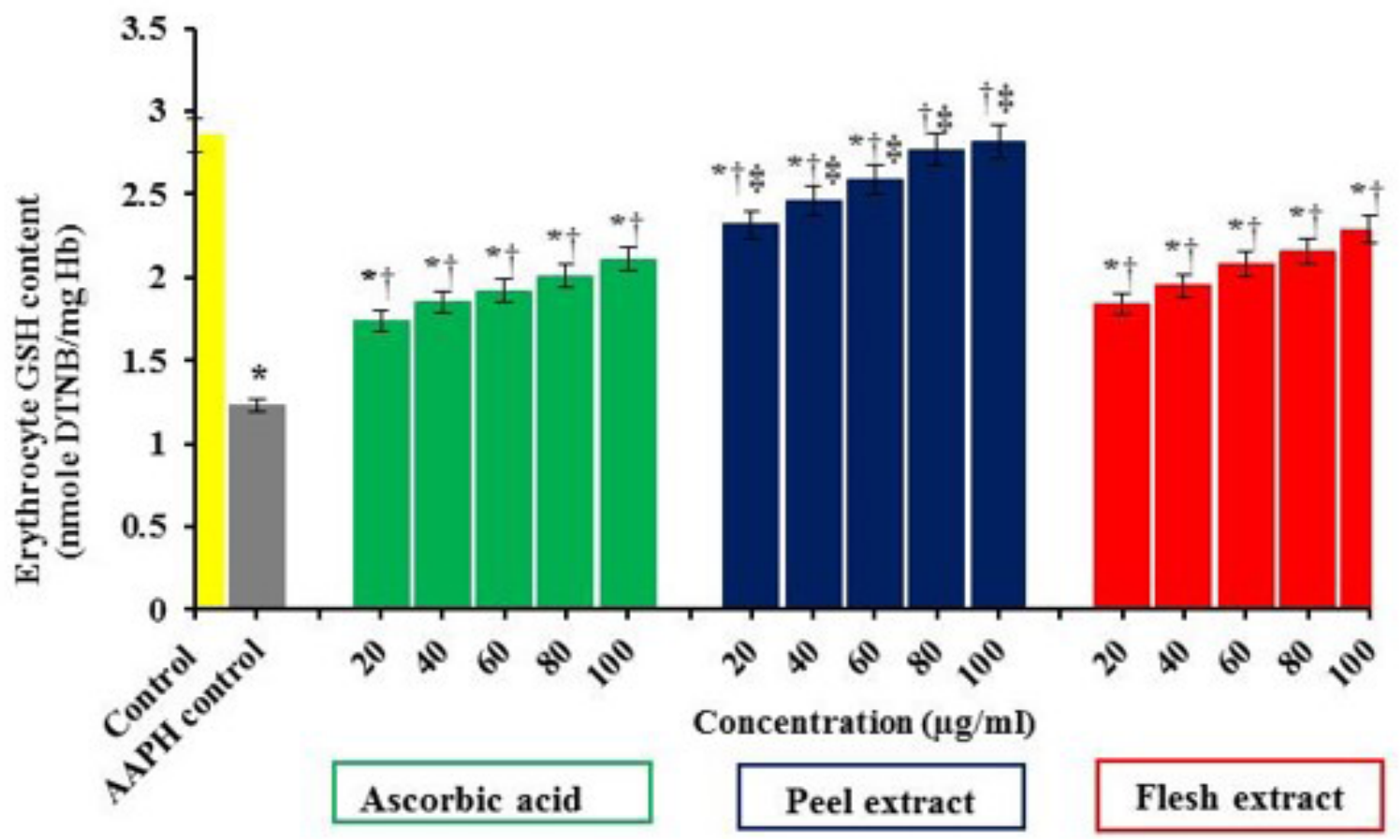

Figure 6. The GSH levels of AAPH-induced erythrocytes restored by the kiwi peel and flesh extracts. Erythrocyte suspension at $5 \%$ hematocrit was incubated with PBS (control) or pre-incubated with different concentrations of peel, flesh or ascorbic acid (20-100 $\mu \mathrm{g} / \mathrm{ml})$ for $30 \mathrm{~min}$. Then erythrocytes were incubated with AAPH $(25 \mathrm{mM})$ for $3 \mathrm{~h}$. Erythrocyte GSH content was expressed as nmole/mg Hb. Values are expressed as Mean $(\mathrm{n}=3) \pm \mathrm{SD}$. *: Results are significant at $\mathrm{p}<0.05$ compared with untreated control cells. $\uparrow$ : Results are significant at $\mathrm{p}<0.05$ compared with cells treated with AAPH alone. $\$$ : Results of flesh extract or peel extract are significant at $\mathrm{p}<0.05$ compared with the same concentration of ascorbic acid. AAPH: $2,2^{\prime}$-azobis (2-amidinopropane) dihydrochloride; DTNB: 5, 5-dithiobis-2-nitrobenzoic acid; GSH: Glutathione; PBS: Phosphate buffer saline; SD: Standard deviation. 
a range of oxygen radicals that can trigger oxidative damage to numerous biomolecules causing ageing, cancer and numerous diseases (Dastmalchi et al., 2020).

\section{Superoxide anion scavenging activity}

The level of superoxide inhibition action of flesh, skin, in contrast with ascorbic acid (Figure 7a) ranged from 31.1 to $60.3 \%$, 50.8 to $79.1 \%$ and 57.4 to $87.7 \%$, respectively. Concerning $\mathrm{IC}_{50}$, it was $27.00,9.84$, and $8.71 \mu \mathrm{g} / \mathrm{ml}$ for flesh, peel and ascorbic acid, respectively. These results revealed that the extract of the skin part exhibits the approximately triple strength of the flesh part towards superoxide anion $(p<0.05)$. Indeed, referring to the standard compound, $\mathrm{IC}_{50}$ of kiwi peel is nearly the ascorbic acid $\mathrm{IC}_{50}$ with no considerable difference. This may be linked to the presence of phenolic compounds in particular p-coumaric, ferulic, which have not been detected in the flesh extract (Table 1). According to Dastmalchi et al. (2020) explanation, phenolic compounds react with free radicals, give them electrons, and facilitate the conversion of free radicals to a stable formula.

\section{Hydroxyl radical scavenging activity}

Figure $7 \mathrm{~b}$ clarified the dose-dependent curve of the $\mathrm{HO}$ scavenging activities of kiwi flesh and peel extracts separately relative to ascorbic acid. $\mathrm{H}_{2} \mathrm{O}_{2}$ scavenging power of the flesh, peel, and ascorbic acid increased from 66.6 to $80.9 \%, 77.9$ to $90.4 \%$ and 84.4 to $91.5 \%$, respectively by elevating the extract concentration from 20 to $40 \mu \mathrm{g} / \mathrm{ml}$. The increment in concentration of the extract slightly, without significant differences, raises the free hydroxyl radical scavenging percentage to the maximum at $100 \mu \mathrm{g} / \mathrm{ml}$. Ascorbic acid had a relatively greater activity related to the flesh. Starting from the concentration of $80 \mu \mathrm{g} / \mathrm{ml}$, the kiwi peel's $\mathrm{H}_{2} \mathrm{O}_{2}$ scavenging was marginally higher than that
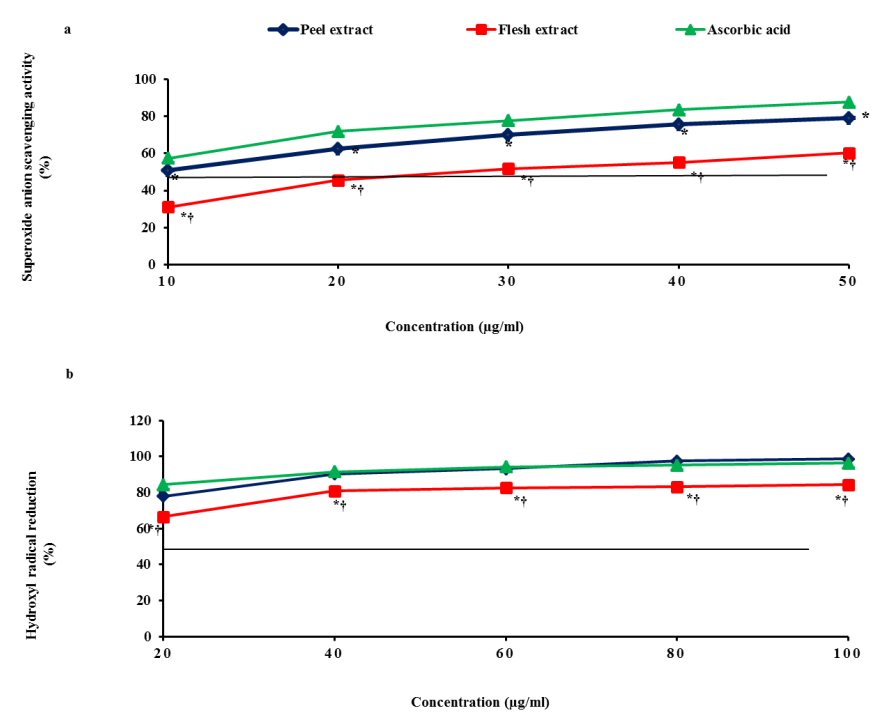

Figure 7. (a) Superoxide anion scavenging activity; (b) Hydroxyl radical reduction activity of kiwi peel and flesh extract comparing with ascorbic acid. ${ }^{*}$ Results of flesh or peel extract are significant at $\mathrm{p}<0.05$ compared with ascorbic acid. $\dagger$ Results of flesh extract are significant at $\mathrm{p}<0.05$ compared with the peel extract. of standard ascorbic acid. The least $\mathrm{IC}_{50}$ value was disclosed by ascorbic acid $(11.84 \mu \mathrm{g} / \mathrm{ml})$ followed by peel extract $(12.83 \mu \mathrm{g} / \mathrm{ml})$ then flesh extract $(15.01 \mu \mathrm{g} / \mathrm{ml})$. Relative to the extract of peel and pure ascorbic acid, the flesh ethanol extract separately showed a considerable $(p<0.05)$ higher $\mathrm{IC}_{50}(16.99 \%$ and $26.77 \%$, correspondingly). Again, no substantial difference was noticed between $\mathrm{IC}_{50}$ of kiwi's peel extract and vitamin C (standard) which confirmed the potent scavenging effect of these fruit peels. A previous study done by Bursal \& Gülçin (2011) also reported the antioxidant and antiradical activities of Actinidia deliciosa against superoxide anion and hydroxyl radical compared to the standard antioxidant compounds.

\section{Conclusion}

In conclusion, the results of the current study established the cytotoxicity of the kiwi fruit flesh extract against PANC-1 cell line. Also, attributable to its content of antioxidants, the peel extract of this fruit showed an effective anti-hemolytic activity against AAPH-prompted hemolysis and lipid peroxidation. Additional research is required to prove the anticancer mechanism of the kiwifruit parts in animal models, to understand the therapeutic power of this fruit on pancreatic cancer and the potential benefits for clinical practice in the future.

\section{References}

Aizikovich, A. (2020). Anticancer effect of new cannabinoids derived from tetrahydrocannabinolic acid on PANC-1 and AsPC-1 human pancreas tumor cells. Journal of Pancreatic Cancer, 6(1), 40-44. http:// dx.doi.org/10.1089/pancan.2020.0003. PMid:32642629.

Alim, A., Li, T., Nisar, T., Ren, D., Zhai, X., Pang, Y., \& Yang, X. (2019). Antioxidant, antimicrobial, and antiproliferative activity-based comparative study of peel and flesh polyphenols from Actinidia chinensis. Food and Nutrition Research, 63, 1577. http://dx.doi. org/10.29219/fnr.v63.1577. PMid:31073285.

Bae, H., Jayaprakasha, G. K., Crosby, K., Jifon, J. L., \& Patil, B. S. (2012). Influence of extraction solvents on antioxidant activity and the content of bioactive compounds in non-pungent peppers. Plant Foods for Human Nutrition (Dordrecht, Netherlands), 67(2), 120128. http://dx.doi.org/10.1007/s11130-012-0290-4. PMid:22569831.

Borra, S. K., Gurumurthy, P., Mahendra, J., Jayamathi, K. M., Cherian, C. N., \& Ram, C. (2013). Antioxidant and free radical scavenging activity of curcumin determined by using different in vitro and ex vivo models. Journal of Medicinal Plants Research, 7, 2680-2690. http://dx.doi.org/10.5897/JMPR2013.5094.

Brindisi, M., Bouzidi, L., Frattaruolo, L., Loizzo, M. R., Tundis, R., Dugay, A., Deguin, B., Cappello, A. R., \& Cappello, M. S. (2020). Chemical profile, antioxidant, anti-inflammatory, and anti-cancer effects of Italian Salvia rosmarinus Spenn. Methanol leaves extract. Antioxidants, 9(9), 826. http://dx.doi.org/10.3390/antiox9090826. PMid:32899385.

Bursal, E., \& Gülçin, İ. (2011). Polyphenol contents and in vitro antioxidant activities of lyophilised aqueous extract of kiwifruit (Actinidia deliciosa). Food Research International, 44(5), 1482-1489. http://dx.doi.org/10.1016/j.foodres.2011.03.031.

Choi, J., Kang, H. J., Kim, S. Z., Kwon, T. O., Jeong, S., \& Jang, S. (2013). Antioxidant effect of astragalin isolated from the leaves of Morus alba L. against free radical-induced oxidative hemolysis of human red blood cells. Archives of Pharmacal Research, 36(7), 912-917. http://dx.doi.org/10.1007/s12272-013-0090-x. PMid:23512775. 
D’evoli, L., Moscatello, S., Lucarini, M., Aguzzi, A., Gabrielli, P., Proietti, S., Battistelli, A., Famiani, F., Böhm, V., \& Lombardi-Boccia, G. (2015). Nutritional traits and antioxidant capacity of kiwifruit (Actinidia deliciosa Planch., cv. Hayward) grown in Italy. Journal of Food Composition and Analysis, 37, 25-29. http://dx.doi.org/10.1016/j. jfca.2014.06.012.

Dastmalchi, N., Baradaran, B., Latifi-Navid, S., Safaralizadeh, R., Khojasteh, S. M. B., Amini, M., Roshani, E., \& Lotfinejad, P. (2020). Antioxidants with two faces toward cancer. Life Sciences, 258, 118186. http://dx.doi.org/10.1016/j.lfs.2020.118186. PMid:32768586.

Didry, N., Dubreuil, L., \& Pinkas, M. (1990). New procedure for direct bioautographic TLC assay as applied to a tincture of Ranunculus bulbosus. Journal of Ethnopharmacology, 29(3), 283-290. http:// dx.doi.org/10.1016/0378-8741(90)90039-V. PMid:2214814.

Fan, M., Chen, G., Zhang, Y., Nahar, L., Sarker, S. D., Hu, G., \& Guo, M. (2020). Antioxidant and Anti-proliferative properties of Hagenia abyssinica roots and their potentially active components. Antioxidants, 9(2), 143. http://dx.doi.org/10.3390/antiox9020143. PMid:32041310.

Food and Agriculture Organization of the United Nations - FAO. (2019). Crop production, statistics, division. Rome: FAOSTAT. Retrieved from http://faostat.fao.org

García-Sánchez, A., Miranda-Díaz, A. G., \& Cardona-Muñoz, E. G. (2020). The role of oxidative stress in physiopathology and pharmacological treatment with Pro- and antioxidant properties in chronic diseases. Oxidative Medicine and Cellular Longevity, 2020, 2082145. http://dx.doi.org/10.1155/2020/2082145. PMid:32774665.

Kim, J. G., Beppu, K., \& Kataoka, I. (2009). Varietal differences in phenolic content and astringency in skin and flesh of hardy kiwifruit resources in Japan. Scientia Horticulturae, 120(4), 551-554. http:// dx.doi.org/10.1016/j.scienta.2008.11.032.

Kunwar, A., Mishra, B., Barik, A., Kumbhare, L. B., Pandey, R., Jain, V. K., \& Priyadarsini, K. I. (2007). 3, 3'-Diselenodipropionic acid, an efficient peroxyl radical scavenger and a GPx mimic, protects erythrocytes (RBCs) from AAPH-induced hemolysis. Chemical Research in Toxicology, 20(10), 1482-1487. http://dx.doi.org/10.1021/ tx700137a. PMid:17900173.

Leontowicz, M., Jesion, I., Leontowicz, H., Park, Y. S., Namiesnik, J., Jastrzebski, Z., Katrich, E., Tashma, Z., \& Gorinstein, S. (2014). Bioactivity and bioavailability of minerals in rats loaded with cholesterol and kiwi fruit. Microchemical Journal, 114, 148-154. http://dx.doi.org/10.1016/j.microc.2013.12.015.

Lim, S., Han, S. H., Kim, J., Lee, H. L., Lee, J. G., \& Lee, E. J. (2016). Inhibition of hardy kiwifruit (Actinidia aruguta) ripening by 1 -methylcyclopropene during cold storage and anticancer properties of the fruit extract. Food Chemistry, 190, 150-157. http://dx.doi.org/10.1016/j.foodchem.2015.05.085. PMid:26212954.

Ma, T., Lan, T., Ju, Y., Cheng, G., Que, Z., Geng, T., Fang, Y., \& Sun, X. (2019). Comparison of the nutritional properties and biological activities of kiwifruit (Actinidia) and their different forms of products: towards making kiwifruit more nutritious and functional. Food \& Function, 10(3), 1317-1329. http://dx.doi.org/10.1039/ C8FO02322K. PMid:30694282.

Miki, M., Tamai, H., Mino, M., Yamamoto, Y., \& Niki, E. (1987). Free-radical chain oxidation of rat red blood cells by molecular oxygen and its inhibition by $\alpha$-tocopherol. Archives of Biochemistry and Biophysics, 258(2), 373-380. http://dx.doi.org/10.1016/00039861(87)90358-4. PMid:3674881.

Neha, K., Haider, M. R., Pathak, A., \& Yar, M. S. (2019). Medicinal prospects of antioxidants: a review. European Journal of Medicinal
Chemistry, 178, 687-704. http://dx.doi.org/10.1016/j.ejmech.2019.06.010. PMid:31228811.

Nishikimi, M., Appaji Rao, N., \& Yagi, K. (1972). The occurrence of superoxide anion in the reaction of reduced phenazine methosulfate and molecular oxygen. Biochemical and Biophysical Research Communications, 46(2), 849-854. http://dx.doi.org/10.1016/S0006291X(72)80218-3. PMid:4400444.

Park, Y. S., Leontowicz, H., Leontowicz, M., Namiesnik, J., Suhaj, M. M., Cvikrová, M., Martincová, O., Weisz, M., \& Gorinstein, S. (2011). Comparison of the contents of bioactive compounds and the level of antioxidant activity in different kiwifruit cultivars. Journal of Food Composition and Analysis, 24(7), 963-970. http://dx.doi. org/10.1016/j.jfca.2010.08.010.

Peticila, A., Scaeteanu, G. V., Madjar, R., Stanica, F., \& Asanica, A. (2015). Fertilization effect on mineral nutrition of Actinidia deliciosa (kiwi) cultivated on different substrates. Agriculture and Agricultural Science Procedia, 6, 132-138. http://dx.doi.org/10.1016/j. aaspro.2015.08.049.

Podsedek, A., Majewska, I., Redzynia, M., Sosnowska, D., \& Koziołkiewicz, M. (2014). In vitro inhibitory effect on digestive enzymes and antioxidant potential of commonly consumed fruits. Journal of Agricultural and Food Chemistry, 62(20), 4610-4617. http://dx.doi. org/10.1021/jf5008264. PMid:24785184.

Qin, B., Yang, K., \& Cao, R. (2020). Synthesis, radical-scavenging activities, and protective effects against $\mathrm{AAPH}$-induced oxidative damage in DNA and erythrocytes of piperine derivatives. Journal of Chemistry, 026286, 1-12. http://dx.doi.org/10.1155/2020/9026286.

Rajendra Prasad, N., Karthikeyan, A., Karthikeyan, S., \& Reddy, B. V. (2011). Inhibitory effect of caffeic acid on cancer cell proliferation by oxidative mechanism in human HT-1080 fibrosarcoma cell line. Molecular and Cellular Biochemistry, 349(1-2), 11-19. http://dx.doi. org/10.1007/s11010-010-0655-7. PMid:21116690.

Rashidpoura, S., Zahedipourb, F., Karimia, G., \& Jamialahmadie, K. (2021). Protective effects of Osthole against free radical-induced hemolysis of erythrocytes. Pharmaceutical Sciences, 27(1), 56-62. http://dx.doi.org/10.34172/PS.2020.65.

Russo, G. L., Russo, M., Spagnuolo, C., Tedesco, I., Bilotto, S., Iannitti, R., \& Palumbo, R. (2014). Quercetin: a pleitropic kinase inhibitor against cancer. Cancer Treatment and Research, 159, 185-205. http:// dx.doi.org/10.1007/978-3-642-38007-5_11. PMid:24114481.

Salama, Z. A., Aboul-Enein, A. M., Asker, M. S., Gaafar, A. A., Hanan, A. F., Abou-Elella, F., \& Ahmed, H. A. (2018). Active constituents of kiwi (Actinidia deliciosa Planch) peels and their biological activities as antioxidant, antimicrobial and anticancer. Research Journal of Chemistry and Environment, 22, 52-59.

Sharifi-Rad, M., Anil Kumar, N. V., Zucca, P., Varoni, E. M., Dini, L., Panzarini, E., Rajkovic, J., Tsouh Fokou, P. V., Azzini, E., Peluso, I., Prakash Mishra, A., Nigam, M., El Rayess, Y., Beyrouthy, M. E., Polito, L., Iriti, M., Martins, N., Martorell, M., Docea, A. O., Setzer, W. N., Calina, D., Cho, W. C., \& Sharifi-Rad, J. (2020). Lifestyle, oxidative stress, and antioxidants: back and forth in the pathophysiology of chronic diseases. Frontiers in Physiology, 11, 694. http://dx.doi. org/10.3389/fphys.2020.00694. PMid:32714204.

Singh, R. P., Chidambara Murthy, K. N., \& Jayaprakasha, G. K. (2002). Studies on the antioxidant activity of pomegranate (Punica granatum) peel and seed extracts using in vitro models. Journal of Agricultural and Food Chemistry, 50(1), 81-86. http://dx.doi.org/10.1021/ jf010865b. PMid:11754547.

Singleton, V. L., Rudolf, O., \& Rosa, M. (1999). Analysis of total phenols and other oxidation substrates and antioxidants by means of Folin- 
Ciocalteu reagent. Methods of Enzymology, 299, 152-178. https:// doi.org/10.1016/S0076-6879(99)99017-1.

van de Loosdrecht, A. A., Beelen, R. H. J., Ossenkoppele, G. J., Broekhoven, M. G., \& Langenhuijsen, A. C. (1994). A tetrazolium-based colorimetric MTT assay to quantitate human monocyte mediated cytotoxicity against leukemic cells from cell lines and patients with acute myeloid leukemia. Journal of Immunological Methods, 174(1-2), 311-320. https://doi.org/10.1016/0022-1759(94)90034-5.

Vattem, D. A., \& Shetty, K. (2005). Biological function of ellagic acid: a review. Journal of Food Biochemistry, 29(3), 234-266. http://dx.doi. org/10.1111/j.1745-4514.2005.00031.x.

Wang, Q., Luo, J., Liu, H., Brennan, C. S., Liu, J., \& Zou, X. (2019). Protective effects of the flavonoid fraction obtained from pomelo fruitlets through ultrasonic associated microwave extraction against AAPH induced erythrocyte hemolysis. RSC Advances, 9(28), 1600716017. http://dx.doi.org/10.1039/C9RA02523E.

Wang, Y., Li, L., Liu, H., Zhao, T., Meng, C., Liu, Z., \& Liu, X. (2018). Bioactive compounds and in vitro antioxidant activities of peel, flesh and seed powder of kiwi fruit. International Journal of Food Science \& Technology, 53(9), 2239-2245. http://dx.doi.org/10.1111/ ijfs.13812.

Yang, H. L., Korivi, M., Lin, M., Chang, H., Wu, C., Lee, M., Chen, W., \& Hseu, Y. (2017). Antihemolytic and antioxidant properties of pearl powder against 2,2'-azobis(2-amidinopropane) dihydrochlorideinduced hemolysis and oxidative damage to erythrocyte membrane lipids and proteins. Journal of Food and Drug Analysis, 25(4), 898907. http://dx.doi.org/10.1016/j.jfda.2016.10.007. PMid:28987367.

Zhang, J., Fu, Y., Yang, P., Liu, X., Li, Y., \& Gu, Z. (2020). ROS scavenging biopolymers for anti-inflammatory diseases: classification and formulation. Advanced Materials Interfaces, 7(16), 2000632. http:// dx.doi.org/10.1002/admi.202000632.

Zhang, J., Hou, X., Ahmad, H., Zhang, H., Zhang, L., \& Wang, T. (2014). Assessment of free radicals scavenging activity of seven natural pigments and protective effects in AAPH-challenged chicken erythrocytes. Food Chemistry, 145, 57-65. http://dx.doi.org/10.1016/j. foodchem.2013.08.025. PMid:24128449.

Zhao, C. N., Meng, X., Li, Y., Li, S., Liu, Q., Tang, G. Y., \& Li, H. B. (2017). Fruits for prevention and treatment of cardiovascular diseases. Nutrients, 9(6), 598. http://dx.doi.org/10.3390/nu9060598. PMid:28608832.

Zuo, L. L., Wang, Z. Y., Fan, Z. L., Tian, S. Q., \& Liu, J. R. (2012). Evaluation of antioxidant and antiproliferative properties of three Actinidia (Actinidia kolomikta, Actinidia arguta, Actinidia chinensis) extracts in vitro. International Journal of Molecular Sciences, 13(5), 5506-5518. http://dx.doi.org/10.3390/ijms13055506. PMid:22754311. 